\title{
The Lost World of Twemlow and Kent-Watson: Mancunian Exploitation Film in the 1980s and 1990s
}

\begin{abstract}
Andy Willis and C. P. Lee
Films which have been exclusively distributed and exhibited outside the traditional conception of the film theatre or cinema have gained very little critical attention within film and media studies. In the case of domestic formats such as VHS this can be partly explained by the fact that, as Barbara Klinger notes, 'film exhibition via television in the casual setting of the home still appears to constitute a break with the quality and mesmerizing power of cinema in the motion picture theatre' (2006: 63). While this attitude to domestic exhibition may be slowly changing, largely due to HD formats and digital cinema projection bringing the two spheres closer together in the twenty-first century, in the 1980s the terms 'straight to video' and 'direct to video' were, when it came to mainstream films, widely accepted to indicate low-budget, poor-quality products not worthy of theatrical distribution. The negative connotations of the term 'direct to video' have meant that the work of a number of innovative film-makers, producing what might be described as broadly mainstream work and designed to be consumed domestically on video, has been omitted from the various histories of cinema. Indeed, the only really sustained attempts to explore video film production and distribution in Britain during the 1980s have focused on organisations and film-makers associated with alternative and avant-garde practice. In this article we want to redress this imbalance by focusing on the almost forgotten video film-making of Manchester-based Cliff Twemlow and David Kent-Watson.

Between 1982 and 1992 this enthusiastic duo took notice of the newly available video technology and used it to build an unlikely career within, or rather on the outer fringes of, the British film industry. These two men were musician, actor, writer and one-time nightclub bouncer Cliff Twemlow and recording studio owner, soundman, cameraman and, latterly, film director David Kent-Watson. In this
\end{abstract}


article we want to argue that the films these men and their associates worked on over that ten-year period are essential examples of British exploitation cinema and should be central rather than peripheral to any understanding of the history of low-budget commercial filmmaking in the UK during the 1980s. However, Twemlow and KentWatson have been sadly overlooked and neglected by critics and academics, and consequently a re-evaluation of their little known oeuvre is long overdue. Films such as G.B.H. (1983) and its sequel Lethal Impact (1991), The Ibiza Connection (1984), The Assassinator (1988), Firestar: First Contact (1991) and The Eye of Satan (1992) reveal a largely unknown, forgotten or 'lost world' of Twemlow and KentWatson, a world of film and film-making that, for those interested in the history of British exploitation cinema, is easily as important as that other recent discovery from the North West of England, the much more critically celebrated and feted 'lost world' of regional film-makers Mitchell and Kenyon.

\section{Background}

David Kent-Watson and Cliff Twemlow met in Manchester through their involvement in the regional television industry of the 1960s. Twemlow had been a nightclub bouncer before realising that he could make an easier and less violent living as an extra on the television productions being made in the city by Granada. As Twemlow himself put it, 'Obtaining an Equity membership card, I enrolled as an extra and was seen to appear on Granada's Coronation Street (Granada 1960-) playing darts and slopping about the Rovers, smiling into the camera's lens trying to get noticed' (1980: 50). It was while appearing as such a 'background artist' that he got to know one of the studio's soundmen, David Kent-Watson. It was also during this period that Twemlow, who had long been interested in music, began to record and publish his work under the pseudonym Peter Reno. ${ }^{1}$ He was now able to move fully into the music world by providing library and stock background music for film, television and radio, and

within a comparatively short time, I had compiled a staggering total of two thousand compositions under the pen name 'Peter Reno'. Most of the compositions were recorded and used for incidental music, while a selection were adapted for T.V. themes ... The rewards were astronomical. $£ 20,000.00$ a year was soon to be derived from my music. (ibid.: 54) 
He certainly proved successful in this endeavour and created musical work that would be included in television programmes such as the long-running daytime drama Crown Court (Granada 1972-84) and Queenie's Castle (Yorkshire 1970-2), as well as a number of European documentaries. In fact, according to IMDb Pro.com, Twemlow's prolific alter ego P. Reno is credited as providing the stock music for at least six short documentaries in 1971 alone. $^{2}$

Probably in an attempt to disguise the small number of people working on their features, Twemlow would later return to the use of a variety of aliases, such as Mike Sullivan, for his various and multi-faceted film activities. These film-making roles would ultimately include acting, producing and scripting as well as writing songs and musical scores for many of the Twemlow and Kent-Watson productions. One of Twemlow's many pseudonyms was John Agar, the use of which perhaps reveals a knowledge and awareness of exploitation cinema, as Agar, an American actor once married to Shirley Temple, had appeared in numerous low-budget movies in the USA including, in 1958 alone, Jet Attack and Attack of the Puppet People. Agar had also made an appearance in the western Johnny Reno (1966), thus linking Twemlow's use of the name Reno to Agar and further suggesting a wide knowledge of the popular cinema of the day. In the meantime, David Kent-Watson had moved on from his position at Granada and established the Indigo recording studios in Manchester's city centre, with one of its primary aims being the recording of Twemlow's compositions. Kent-Watson recalls that it was at Indigo that I closely became involved with Cliff Twemlow in recording hundreds of his compositions for de Wolf's music library'. ${ }^{3}$ The highlight of the pair's musical partnership was the 1973 recording of a Twemlow-composed song entitled 'Live and Let Die' which was performed by singer Salena Jones and released by Indigo Records. Initially the song made positive waves and was selected by Terry Wogan as his Record of the Week. However, as Twemlow recalled, the timing of its appearance close to the opening of the James Bond film of the same name did not go unnoticed:

Shortly after the release, an injunction was slammed on my song and Court Proceedings were taken by Paul McCartney who had been commissioned to write the main title for the film. The court sympathised with the Broccoli empire (but of course) and my record was withdrawn from the market. Court costs were set against me and Indigo records. (1980: 55) 
Even though this brush with the film business had proved disappointing, in 1980 Kent-Watson's Indigo company relocated to King Street West in Manchester's city centre and expanded its operations to include video production. It was during this period that Twemlow also became increasingly interested in film-making.

After a number of personal problems, Twemlow had returned to working on the doors of some of Manchester's more upmarket nightclubs in the late 1970s. However, during this period he continued to pursue his creative ambitions and realised another of his longterm dreams by becoming an author through the publication of the genre novels The Pike (1982) and The Beast of Kane (1983). These works followed on from his telling the story of his own experiences as a bouncer and his subsequent movement into the world of music in the pages of his literary debut, The Tuxedo Warrior (1980). The rights to this autobiographical book were sold and, under the same title, it was made into an international film production in 1982 and starred John Wyman, Carol Royle, Holly Palance and James Coburn Jnr. Ultimately, it was this that led to the development of Twemlow and Kent-Watson's exploitation film career. However, for those who had read Twemlow's original, the film was certainly a strangely unfamiliar affair. The autobiographical account had told the story of Twemlow's experiences as a bouncer and aspirant musician and was set in the clubs and nightlife of Manchester, Morecombe and Glasgow. But while retaining the tough, hard-drinking central character of Cliff, the book was substantially altered by the film's director and scriptwriter Andrew Sinclair and by its production company; the location became Zimbabwe and the story was changed to incorporate gangsters and diamond thieves, leaving very little of the original apart from the striking title. However, whatever he may have felt about the final product, Twemlow was paid $£ 25,000$ for the rights to the novel and was also given a small part as a 'heavy' as well as being hired as a stunt arranger on the project.

The resultant Tuxedo Warrior may have lacked what most critics would consider 'quality' but it certainly whetted Cliff Twemlow's appetite for film-making. As soon as he returned to Manchester he contacted his old associate Kent-Watson with a proposal: he would put his $£ 25,000$ towards the budget for the production of a film if the latter would allow them to use the facilities at his newly established video production company, now known simply as ICE (Indigo Commercial Enterprises) and help with the film-making. Together the pair formed the nucleus of what would quickly become a regional film-making enterprise, with Kent-Watson directing and acting as camera operator and Twemlow 
working as a scriptwriter and lead actor as well as contributing songs and scores. In an article in the local Eccles Journal on 28 October 1982, Twemlow stated that 'our aim is to set up a film industry in the Manchester area, why shouldn't films be set in Eccles?' However, as they were developing their ideas, Kent-Watson and Twemlow quickly realised that their money would be very unlikely to stretch to a fully fledged feature-length production on film. The pair then made a most significant decision, one which would enable them to continue making films for almost a decade: to exploit the newly developing and expanding video technology and shoot and distribute their film on tape. Kent-Watson has stated that they felt they had no other choice but to shoot on video, given that they had only $£ 25,000$ to spend, and he has also said that as the equipment at his ICE studios was not up to broadcast standard they never envisaged making films which would be suitable for showing on British television. Importantly, this choice also allowed them to include material that at the time would have been deemed too racy or violent for mainstream television and also to explore a range of genres that were, for the most part, consumed primarily in the cinema at that time. However, the rapid expansion of domestic video technology was taking those action-based genres out of the film theatre and bringing them into the home.

\section{New opportunities and the emergence of video technology}

As the boom in VCR ownership developed in the 1980s, videocassettes offered an important mode of distribution for feature films. In the context of the USA, low-budget, exploitation film-makers who had previously placed their products in drive-in theatres and inner-city cinemas now saw the emergence of a new distribution network which they could utilise. Video, which initially had been seen as a threat by the Hollywood studios, was rapidly embraced by exploitation producers and distributors. Brian Austin noted at the time: 'The impact of home video ... may have important consequences for independent (those not tied to the studios) film-makers. In particular, new markets for the products of the Hollywood outsiders could result. Already we have seen independent production of horror/slasher films targeted to the teenage audience in the home' (1990: 340). In Britain, the late 1970 s and early 1980s saw a particularly rapid take-up of the new domestic video technology and, again, this expansion allowed for a new marketplace to develop, one that offered films on videotape to be watched exclusively at home. With the cost of pre-recorded tapes at around $£ 80$ to $£ 100$, the most common way to get hold of these was to hire them from the expanding number of video rental outlets, some 


\section{The Lost World of Twemlow and Kent-Watson}

of which specialised in this business while others were run as sidelines in locations such as petrol stations, newsagents and local foodstores. However, the number of films available at this time must be put into context. According to David Kerekes and David Slater: 'At the end of 1980 , there were a modest 600 pre-recorded videocassette titles available in Britain ... By 1981 the choice had more than doubled' (2000: 16). Many of these titles were drawn from the ranks of what would traditionally be termed 'exploitation' films, in particular those that foregrounded violence. It was in this context that some producers and distributors decided it might be worthwhile rejecting theatrical exhibition in favour of the much cheaper video release, and hence the first experiments in films made directly for video distribution.

The idea of 'direct to video' releases has always had an association with the exploitation end of the film industry. Linda Ruth Williams (2005) has noted the link between this style of distribution/exhibition and the erotic thriller, while M. Ray Lott (2004) has discussed its importance to the producers of low-budget American martial arts films in the late 1980s and 1990s. But of course the genre most associated with the technology of the domestic video is pornography. It is these associations which have had a negative effect on the critical standing and perception of 'direct to video' works, with many viewers seeing them as invariably poorer in terms of both production values and their ability to create engaging and original stories. In other words, for a large number of critics and consumers films went direct to video because they were simply not worthy of a theatrical release. Of course, this only tells part of the story and often applies to Hollywood films that were unsuccessful on their US theatrical release rather than to the low-budget exploitation fare which had become staple video product in this period. On the periphery of the film industry the new domestic technology was positively embraced and, in due course, films were conceived, designed, shot and ultimately realised solely for video release.

The changes in the potential ways in which low-budget films were exhibited in the late 1970 s and early 1980 s-for example, cable television, laserdisc as well as video - were good news for producers and meant that, as Linda Ruth Williams has argued: 'Low budget producers ... responded to the challenge of the blockbuster by diversifying their sales options, [and] as the VHS machine became an established feature of the domestic space, making films only or primarily for video release' (2005: 6). However, before the consolidation of the 'straight to video' market, a number of cinematic explorers did attempt to chart these then unknown waters, and these most certainly included Twemlow and Kent-Watson with their low-budget 
action-orientated films aimed solely at the domestic video market. As we have noted, their trailblazing work has gone largely unnoticed by those who have written about the opportunities video technology and tape offered distribution in the UK. The unashamedly commercial genre products which they produced in the 1980s did not find favour with writers such as Sean Cubitt, whose 1991 book on video culture, Timeshift, focuses almost exclusively on experimental and communitybased film-makers and the opportunities which video provided for them. For Cubitt, 'distribution of video work is largely accomplished through small specialist houses-Albany Video, London Video Arts, Team Video, Concorde, Cinema of Women, The Other Cinema and Circles Feminist Distributors' (150). Due to their overtly commercial, generic nature, the historical importance of films such as G.B.H. as well as of companies like ICE Productions has undoubtedly been marginalised by the fact that they do not fit the radical agenda of such writers and historians. However, as we shall explore below, the underlying assumption that these films could not in some way engage progressively with social issues in Britain in the early 1980s is sorely misplaced. More recently writers such as Julia Knight (2006) have revisited the potential that video distribution offered in the UK in the 1980s, but she too has ignored the possibilities which the Twemlow and Kent-Watson model offered for commercial film-makers, once again preferring to focus on avant-garde and community-based products and distributors. However, it is disappointing that the clearly generic products of ICE fall outside these models of alternative practice as they too offer an alternative version of independent production and distribution and reveal that there was more work being produced on video than the current histories of the form acknowledge. Alongside this, the lack of availability of this work since its first appearance on tape has also meant that its rediscovery and critical reassessment has not yet fully taken place.

\section{The importance of genre to the Twemlow and Kent-Watson project}

Sarah Street has noted:

Ironically, the years of Thatcherism provided the political-cultural background to the revival of British cinema in the 1980s. While Thatcher's commitment to the market economy offered little assistance to film producers ... a fortunate combination of temporary tax incentives, the multiplex boom and the international success of heritage costume films saved the industry from extinction. (1997: 102) 
However, that revival did not automatically lead to an increase in production of British-made straight-ahead genre and actionorientated films. One of the reasons for this is highlighted by John Hill, who has argued that:

British genre cinema has historically depended upon a home market of sufficient size to allow profitability. As a result of falling audiences, this kind of cinema became increasingly difficult to sustain from the 1970s onwards and, during the 1980s, British film-making began (under the influence of television) to move in the direction of art cinema. (1999: 160)

However, the films of Kent-Watson and Twemlow show that beyond the London-based mainstream of British film-making, and outside the oft-cited binary of heritage and social-realist styles, a British exploitation cinema based on action genre film production did actually survive and, within its own limited ambitions, flourish for almost a decade. During their decade-long career Kent-Watson and Twemlow would continue to make films in a number of popular genres. These would variously encompass gangster movies, horror, science fiction and action/adventure, often combining one or more in a heady blend, many of which were laced with high-energy, martial arts-based fight sequences. All of these works, in combining these elements, were clearly designed to appeal to the dominant tastes of a 1980s videorenting audience. This is perhaps most obvious in their first featurelength effort, G.B.H. Grievous Bodily Harm.

\section{G.B.H. Grievous Bodily Harm}

The first production that Kent-Watson and Twemlow finished was the urban gangster film G.B.H. Grievous Bodily Harm. Set in the clubs and underworld of early 1980s Manchester, the story seems at first sight closer to Twemlow's own experiences on the doors of clubs across Britain, and in particular Manchester, than the filmed version of his book The Tuxedo Warrior. Filming on the project began in October 1982 with additional funding being provided by Ingmar Rystrom, head of the Miss Mary of Sweden cosmetics company, who invested in the project under the guise of IR Productions. Rystrom was based in Alderley Edge, Cheshire, and the micro-budget production took advantage of his inclusion in the financing arrangements by using his large house as one of the film's locations. The added investment meant that the novice film-makers could complete G.B.H. in their own way, making the sort of film which they thought would attract an audience. The finished version of the film was released on VHS in March 1983. 
Interestingly, due to the financial vagaries of film distribution and the creative accounting employed when it came to paying profits back to the investors and production companies, this would be the last time that Rystrom would invest in films as he, like so many involved in the film business, found the financial side of the industry difficult to deal with. Thus from that moment on, until they made Firestar: First Contact, most of the pair's films would be financed solely through ICE productions, giving them a high level of independence as they began to explore film-making in a range of popular genres. At this point the duo were working in a manner that made them one of the most independent film-making teams operating in Britain at the time, meaning that they were able to make the films which they wanted in the manner which they wanted.

The G.B.H. project clearly operated in a long-established tradition of exploitation film-making, something which Blandford et al. suggest would most likely produce 'a film with sensationalist value that exploits a contemporary issue or subject or capitalises on more prurient aspects of hit mainstream movies' (2001: 89). This would certainly seem to be the case with G.B.H. which, as Kent-Watson himself has identified, 'followed the success of The Long Good Friday, but with an even smaller budget', adding that the regional location worked for them as 'Manchester was the ideal setting for a film with the same subject of realistic gang violence.' In true exploitation film-making style, the pair quickly followed up the surprise UK box-office success of John Mackenzie's London-set gangster film with their own even more violent take on British gangland and underworld power struggles. However, the main difference between the two titles is that rather than hitting the cinemas with G.B.H., as did the distributors of The Long Good Friday (1980), Twemlow and Kent-Watson, with the assistance of distributor World of Video 2000, hit the racks of the video stores across the UK. In another staple strategy of the exploitation industry, advertising became a vital component in selling their film, in this case by claiming on the front cover that G.B.H. was 'Not for the squeamish' and suggesting that what was contained inside was 'More brutal than The Long Good Friday'. The evocation of Mackenzie's film continued on the back cover where a further attempt to seduce the audience was contained in the promise that:

The Long Good Friday set a new and exciting trend in British Films. Following right on its heels is G.B.H 'Grievous Bodily Harm' starring Cliff Twemlow as Donovan in an even more brutal trip into Manchester's high living, hardhitting clubland. 
With G.B.H., Kent-Watson and Twemlow had produced a film with an ingredient, primarily its violent content, which assisted greatly in selling the film within the new context of video libraries on Britain's high streets and in local garages and corner shops. It might not have been an extreme horror film, the genre which most people associate with this era because of the 'video nasty' panic, but with its blood drenched promotion it appears to have been aimed squarely at a similar young audience to the one which was enjoying watching that genre at home.

Set in the violent Manchester underworld of the early1980s, G.B.H. tells the story of a struggle for power over the control of the doors of some of the city's most high-profile and glamorous nightclubs. It opens with Keller, played by comedian Jerry Harris, and two of his heavies taking over a Manchester nightspot by violently putting its head doorman in hospital and threatening the owner with a shotgun. Murray (Anthony Schaeffer), the owner of another top spot, the Zoo disco, decides that the only way to stop Keller taking over his establishment is to re-employ the legendary doorman Steve Donovan (Twemlow). Following a spectacular helicopter shot of Manchester, the camera picks up Donovan as he leaves Strangeways prison and Murray's right-hand man, Chris (Brett Sinclair), picks him up, thus beginning a story filled with car chases, bar fights and shoot-outs. The panoramic shot of the city is important as it seems designed to draw in the audience by suggesting to them in the opening minutes that the film has higher production values than its later sequences display. However, this sequence is also important because it reveals the ambitious approach which the pair brought to their work. For them, Manchester could look as cinematic and impressive as any other city in the country.

With its underworld setting, struggle for supremacy and violent clashes, G.B.H. is clearly an example of the British gangster film. Given its historical importance as an early example of a 'direct to video' production, it is therefore perhaps a little surprising that it is not mentioned even in passing by any of the contributors to Steve Chibnall and Robert Murphy's 1999 collection British Crime Cinema. A simple explanation would be that the film was not successful and simply vanished without trace before it could make its way into books about British cinema or the crime genre. However, even though its distribution was not easy, the film was far from being a failure. According to Kent-Watson, due to the fact that they were something of an unknown quantity and based in Manchester, the pair initially found it difficult to gain distribution for their debut feature. He recalls 
that they began to look around film trade fairs and visited video distribution companies in London and it was through this networking that they eventually made a distribution deal with David Grant's World of Video 2000. Kent-Watson claims that with the aid of their distribution network they managed to sell 9,000 copies of G.B.H. in the first six months of its release, with the film reaching ninth place on the video sales charts. Clearly then, with multiple rentals for each cassette, considerable numbers of people were renting and watching the film, even if these did not include the future writers of the histories of British cinema in the 1980s.

\section{Political readings of G.B.H.}

The Kent-Watson and Twemlow films, as well as the duo's whole approach to film production and distribution, may also be read in relation to the political shifts and changes in Britain in the 1980s. Thus it is certainly possible to see their micro-budget independence as an example of free enterprise and their minimal, multi-tasking crews as undermining the film industry trade unions of the time, both of which would have certainly won them plaudits from Mrs Thatcher's Tory Party. Furthermore, the lone individual heroes going about their vigilante work would also have rung alarm bells in the minds of liberals across the country. However, partly due to the fact that G.B.H. was based in Manchester, it might not be so simple to dismiss the film as irretrievably right wing in terms of both its content and production context. For many people, the 1980s was also a period that saw a deepening of the division between the North and South of England, with the North often represented as resisting the onslaught of the Thatcher government whose ideological stronghold was seen by many as being in the South. This may be a rather loose opposition, and somewhat wide of the actual truth, but this commonplace political shorthand does nonetheless assist a reading of G.B.H. which reclaims the film from being read as simply an endorsement of the values of entrepreneurial capitalism and Thatcherism. There is certainly a strong North/South opposition within the film. Keller, the man trying to take over the nightclubs of Manchester, is clearly, as his accent indicates, a Southerner. Donovan, the hero of the piece, is often referred to by the nickname 'The Mancunian' and obviously represents a different set of values from Keller's. The opposition between London and Manchester gangsters in the 1960s and 1970s is partly the stuff of urban myth, with many older regulars in Manchester and 
Salford pubs telling stories of how Manchester's 'Quality Street Gang', on hearing that the Krays were coming to 'take over' Manchester, went to Piccadilly station, met them, discussed the situation and sent them back to London with a flea in their ear. (For more on this mythical event see Lee 2002: 66-8.) True or not, such North vs. South tensions seem to inform the story of G.B.H., with Donovan representing a straightforward honesty which is challenged by the gun-toting, women-beating 'chancers' unleashed by Keller. In a sense, then, and acknowledging the particular historical moment of the early 1980s, one might construct the following equation: Keller $=$ London $=$ South $=$ Thatcherism, while Donovan $=$ Manchester $=$ North $=$ 'good' old-fashioned values. One might also argue that Donovan is unquestionably the hero of G.B.H. due to his regional identity and his commitment to the city of Manchester, a commitment which is demonstrated by his standing up to the invading southerners and their abhorrent values. In the early 1980s, as Mrs Thatcher began to change the face of Britain, many saw the nation as increasingly locked into just such a North vs. South, tradition vs. change situation. Here, at that historical moment, it might not be too fanciful to argue that Donovan, 'The Mancunian', could be seen as a symbol of resistance to the change that seemed designed to bring cities such as Manchester to their knees, dispensable victims of the Conservative Party's vision of a 'new nation'.

\section{Twemlow and Kent-Watson post-G.B.H.}

Even given its success with domestic renters, one might have expected G.B.H. to have been a one-off production, as the whole British film industry of the period was so very volatile and economically insecure. In fact, such an expectation is far from the truth, as Kent-Watson and Twemlow went on to continue their commitment to exploitation filmmaking based in the North West for a decade after their debut. While the pair always maintained their production base at ICE in Manchester, their later productions would display even more ambition, including as they did a number of exotic locations, often seemingly designed, once again, to disguise the micro-budgets with which the film-makers were working. No doubt these exotic settings were also used because they were thought to appeal to audiences and could be highlighted in the marketing of the films. With these strategies in mind, productions took advantage of Kent-Watson's connections around the world and utilised settings in Barbados, Granada, Malta and Ibiza. When they 
were not in faraway countries on location, their imaginations were put to good use at home. For example, the team transformed the Laser Quest Centre on Whitworth Street in the centre of Manchester into the interiors of a space ship under attack for their most ambitious and expensive production, Firestar: First Contact. Indeed, when one looks at the credits of that 1991 production these clearly reveal that these were more than just a gang of Mancunian amateurs playing at being filmmakers. The film's cast boasts stalwart British character actor Charles Gray and The Stud (1978) star Oliver Tobias. Once again, the use of these actors reveals Twemlow and Kent-Watson's clear understanding of how to sell the finished film to distributors and audiences alike. Therefore, like so many professionals before them, they cast with a view to marketing and so were thinking about how best to reach their target audiences even before they had shot an inch of tape. In this example each 'name' actor was employed for only a limited number of days, appearing in smaller roles that would enable the use of their name above the title on the video box at the least expense.

\section{Conclusions}

For all their success, according to Kent-Watson the pair did not ever feel part of any mainstream film production structure in Britain. It is this outsider status (which might, under different critical circumstances, be seen positively as independence), and their commitment to filmmaking outside London (which could also be seen as a commitment to regionality) allied with a persistent critical snobbery about 'straight to video' productions which, singly or together, may explain the lack of any real critical interest in their work. While being associated with video distribution brought negative connotations, the team's desire to make mainstream genre films also meant that their work fell outside the category of the 'video nasty' (and thus failed to achieve 'cult' status too). The continuing interest in this particular category of 1980s videos in the UK has had the effect of marginalising non-horror exploitation productions of the period. Alongside this, the lack of any acknowledgement of regional exploitation production in Britain in the 1980s has also resulted in a total lack of awareness of the 'lost world' of Twemlow and Kent-Watson.

Finally, we want to argue that the rediscovery of the Twemlow and Kent-Watson films demands a rethinking of the history of British exploitation cinema in the 1980s and early 1990s. While there is an assumption that low-budget exploitation cinema was in terminal 


\section{The Lost World of Twemlow and Kent-Watson}

decline in the 1980s, we would suggest that films such as G.B.H., The Ibiza Connection, Firestar: First Contact and The Assassinator counter such views. Indeed, for those willing to embrace the new technology of the period, exploitation video production still offered the opportunity to shoot fast and cheaply, learn on the job and make just enough profit to keep rolling. Perhaps more than any other British film-makers of the period, Cliff Twemlow and David Kent-Watson understood this, and it is interesting to consider how many more low-budget wonders they would have made had Twemlow not died in 1993, aged 59 , in the early stages of production of the boxing comedy Hogan's Champion.

\section{Notes}

1. According to the Amazon.co.uk entry for the Trunk label's CD 'Unreleased Incidental Music from George A. Romero's Dawn of the Dead', Twemlow's song "Cause I'm a Man' was used in that film.

2. These included La más alta ocasión - La Batalla de Lepanto, Comienza una reforma and Juventud y trabajo as well as a number of travelogues such as Las Rías de Pontevedera, Paradores de turismo del Pirineo.

3. Unless otherwise stated, all quotations from Kent-Watson derive from interviews or correspondence with the authors.

\section{References}

Austin, Brian A. (1990), 'Home video: the second-run "theater" of the 1990s', in Tino Balio (ed.), Hollywood in the Age of Television, London: Unwin Hyman.

Blandford, Steve, Barry Keith Grant and Jim Hillier (2001), The Film Studies Reader, London: Edward Arnold.

Chibnall, Steve and Robert Murphy (eds) (1999), British Crime Cinema, London: Routledge.

Cubitt, Sean (1991), Timeshift: On Video Culture, London: Routledge.

Hill, John (1999), 'Allegorising the nation: British gangster films of the 1980s', in Steve Chibnall and Robert Murphy (eds), British Crime Cinema, London: Routledge.

Kerekes, David and David Slater (2000), See No Evil: Banned Films and Video Controversy, Manchester: Critical Vision.

Klinger, Barbara (2006), Beyond the Multiplex: Cinema, New Technologies, and the Home, Berkeley, CA: University of California Press.

Knight, Julia (2006), 'Video/DVD sell-through: avenues for reaching wider audiences', paper delivered at the International Association for Mass Communication Research, The American University in Cairo, Egypt, July 23-9.

Lee, C. P. (2002), Shake, Rattle and Rain: Popular Music Making in Manchester 1955-1995, Ottery St Mary: Hardinge Simpole.

Lott, M. Ray (2004), The American Martial Arts Film, Jefferson, NC: McFarland.

Street, Sarah (1997), British National Cinema, London: Routledge.

Twemlow, Cliff (1980), The Tuxedo Warrior, Manchester: City Major Ltd.

Williams, Linda Ruth (2005), The Erotic Thriller in Contemporary Cinema, Edinburgh: Edinburgh University Press. 
Andy Willis and C. P. Lee

C. P. Lee is a broadcaster and writer who lectures in the School of Media, Music and Performance at the University of Salford. He has published works on popular music and comedy and is currently researching regional film-making in the North West of England.

Andy Willis lectures in the School of Media, Music and Performance at the University of Salford. He has published works on various aspects of popular and exploitation cinema including Spanish horror and American martial arts movies.

DOI: $10.3366 / \mathrm{E} 1743452109000685$ 